\title{
Breast screening guidelines fuel firestorm
}

$\mathrm{N}$ ew guidelines for breast cancer screening that recommend women avoid routine mammography until age 50 are based on faulty methodology and will result in an "untold number of lives lost" if implemented across Canada, the Canadian Association of Radiologists charges.

The guidelines, released Monday by the Canadian Task Force on Preventive Health Care, recommend against routine mammography screening for most women age 40 to 49 , arguing the "harms and costs of false-positive results, overdiagnosis and overtreatment" outweigh any "significant reductions in the relative risk of death from breast cancer" (www.cmaj.ca/lookup /doi/10.1503/cmaj.110334).

Aimed at settling more than a decade of contentious debate over the recommended frequency and value of breast cancer screening, the guidelines also say that clinical breast exams and self-exams have no benefit and should never be undertaken, and urge that women over 50 only have mammograms every two to three years, instead of every one or two.

But critics say the data on which the guidelines are based is dated.

The recommendation against routine screening of women under the age of 50 who are at average risk of developing breast cancer risk is self-admittedly "weak," and based on "essentially antiquated" and "unbalanced" evidence, argues Dr. Nancy Wadden, chair of the Canadian Association of Radiologist's Mammography Accreditation Program and medical director of the breast screening program for Newfoundland and Labrador. "The task force looked at studies that were over 25 years old [involving] equipment that is outdated and not even available anymore. There's been enormous changes in breast imaging since that time, [and] in addition radiologists' interpretation skills have improved tremendously."

Part of the problem is that randomized control trials have only been conducted on analog mammography, "because digi-

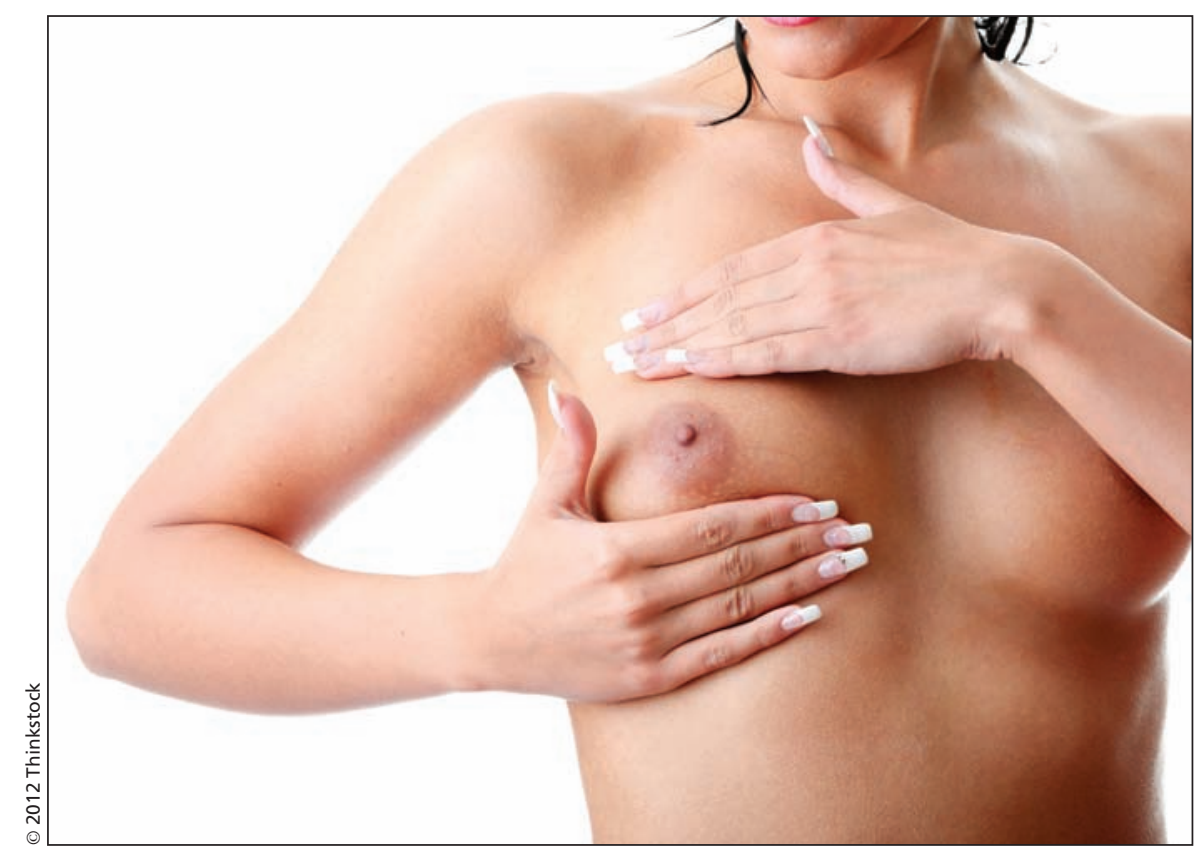

The Canadian Task Force on Preventive Health Care says self-examination of the breasts is of little utility.

tal hasn't been around long enough," adds Dr. Christine Wilson, medical director of the Screening Mammography Program at the British Columbia Cancer Agency.

Wadden contends that more recent observational and community studies indicate that there are "definite benefits" to screening younger women using digital mammography.

But such data "isn't what we would call the best quality of evidence, and again there's still conflicting research out there," counters Gillian Bromfield, director of cancer control policy for the Canadian Cancer Society. She adds that the benefits of routine screening are far lower for women aged 40 to 49 because they are at lower risk of cancer and at higher risk of receiving falsepositive results.

The Canadian Task Force on Preventive Health Care recommendations are consistent with those of the Canadian Cancer Society, which suggest women 50 to 69 should have a mammogram every two years. They also align with national guidelines in Australia, the United Kingdom and the United States.
The task force guidelines state that screening about 2100 women age 40 to 49 years once every two to three years for 11 years would prevent a single death from breast cancer, but it would also result in about 690 women having a false-positive result on a mammogram, and 75 women having unnecessary biopsy of their breast. Moreover, "any positive result from screening has emotional costs such as anxiety and worry for patients and their families, and financial costs to both the patient and the health care system as a result of additional and potentially unnecessary diagnostic tests."

The other side of the coin is underdiagnosis, Wadden argues. Premenopausal cancers tend to be more aggressive and if not undetected early, are more likely to result in negative outcomes, she says. "That's why if we do screen women 40 to 49 , they need to be screened annually."

But proponents of the new guidelines argue that if a cancer is that aggressive, early detection is immaterial.

The disease "spreads so rapidly even 
early detection doesn't make a huge difference in that age group, whereas in the older group it does," says Dr. Walter Rosser, former head of the family medicine department at Queen's University in Kingston, Ontario.

Wadden also took issue with the task force's recommendation for less frequent mammograms for women over the age of 50. "We have data that shows that if women wait more than 30 months to have a mammogram, we get an increase in palpable and later stage cancers, and therefore I strongly disagree with the recommendation for a three-year interval."

Provincial breast cancer screening programs vary substantially, with some provinces such as Alberta, BC and Nova Scotia, routinely providing mammograms to women aged 40 to 49. The task force's recommendations are entirely voluntary and at this point, it's too early to say whether provinces which do provide earlier screening will alter their practices.

Wadden fears that financial pressures will make screening programs for young women an easy target with potentially "tragic" consequences. "I think that if you're an administrator trying to save money, here is too easy a way to save it." — Lauren Vogel, CMAJ

CMAJ 2012. DOI:10.1503/cmaj.109-4062 